centigrammes. In one case 15 centigrammes were injected by error, the patient being a chronic inebriate with congested lungs who was brought in with double malleolar fracture and who refused chloroform. He presented very disquieting symptoms: intense dyspncea, cyanosis, hiccough, thready pulse, headache, and vomiting with faintness. Drycupping to the chest, injections of caffeine, and inhalations of oxygen overcame the symptoms in about a quarter of an hour. He complained of numbness of the legs for two days after the accident. In five instances the anæsthesia was incomplete. Retention of urine was noted in 16 cases, lasting from 18 hours to eight days, and in one instance for two months. In the last-named case the patient also suffered from obstinate constipation which was only overcome 40 days after the operation. Dysuria was complained of five times and lasted for from 24 hours to 10 days. In one instance there was anuria for 24 hours following the injection of ten centigrammes of stovaine for an operation on hæmorrhoids.

The duration of the anæsthesia was from 10 to 100 minutes. This is usually proportional to the amount injected but not invariably so, and in some cases the injection of only 5 centigrammes was followed by prolonged anæsthesia. Perfect anæsthesia in alcoholic and nervous subjects cannot be relied upon with a less dose than 10 centigrammes.

In 11 cases slight headache was complained of and in seven it was severe. Vomiting was only noted on eight occasions during the operation and six times after the operation, either later in the day or on the following day. Rachialgia was complained of once and slight rise of temperature 12 times.

On the whole, the advantages appear to be in favour of spina? stovainisation and I may conclude: 1 . That spinal stovainisation is an excellent mode of inducing anæsthesia which may be employed without danger from 15 years until an advanced age. 2. The dose of stovaine is from 5 to 10 centigrammes ; this affords good anæsthesia which may last one and a half hours. 3. The constitutional disturbances are slight and never interfere with the performance of the surgeon's duties and they seem to be less frequent with stovaine than with cocaine.

The only serious drawback is the comparative frequency of urinary retention (44 out of 146 cases), lasting from one to several days. This drawback, which only exceptionally occurs when cocaine is employed, may not improbably lead me ultimately to give the preference to cocaine in the absence of the contra-indications mentioned above.

Algiers.

\section{Clinical Aftotes:}

\section{MEDICAL, SURGICAL, OBSTETRICAL, AND THERAPEUTICAL.}

\section{NOTE ON A CASE OF HERNIA THROUGH THE FORAMEN OF WINSLOW.}

By T. Carwardine, M.S. Lond., F.R.C.S. Eng., SURGEON TO THE ROYAL INFIRMARY, BRISTOL.

HERNIA through the foramen of Winslow is so rare that the accompanying details of a case may be of interest. An engineer, aged 44 years, whilst using the telephone was suddenly seized with severe colicky pains which made him double up. He was not at first sick but had slight nausea and the pain continued on and off afterwards and prevented sleep. On the next morning he was sick several times on the morning of admission, two days after the onset, he brought up black vomit, so resembling ink in character and smell as to cause inquiries to be made as to whether any ink had been added to the vomit. The patient was dusky, with cold extremities; the pulse was feeble and 124 ; the temperature was $97^{\circ} \mathrm{F}$. The abdomen was distended but not tense except in the epigastrium where there were resistance and impairment of resonance corresponding with the position of the lesser sac of peritoneum. Constipation had been absolute for the last 24 hours.

An immediate operation was performed. The patient was almost pulseless. The bowel, black and lustreless, was discovered on tearing through the gastro-hepatic omentum. A portion of the bowel was reduced, but an uncertain vascular band seemed to prevent reduction of the remainder; and as the patient's condition was bad drainage-tubes were put into the involved gut, the patient dying three hours afterwards.

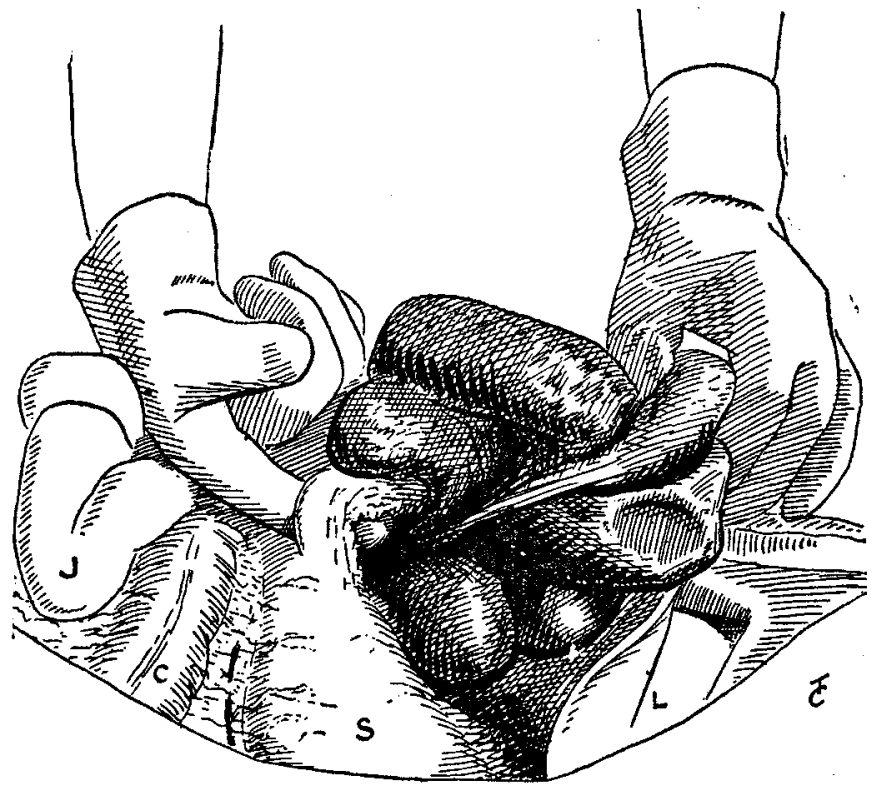

Hernia through the foramen of Winslow. (From a photograph by Professor I. Walker Hall.) S, Stomach. L, Liver. C, Transverse colon. J, Jejunum.

I Professor I. Walker Hall kindly furnished the following notes of the post-mortem examination: "At the autopsy it appeared that about $2 \frac{1}{4}$ feet of the lower end of the ileum were present in the lesser sac. The entering portion had passed over the ascending and right part of the transverse colon, and then into the lesser sac. From the point of entry the lower part of the ileum dragged on the ileo-cæcal valve, the mesentery being twisted so as to form a distinct, sharp edge, simulating a band containing blood-vessels."

The illustration was drawn from a photograph kindly furnished by Professor Walker Hall.

Clifton.

\section{NOTES ON A CASE OF ACUTE GOITRE.}

\section{By Sidney J. O. Dickins, M.D. BRUX., M.R.C.S. ENG.,} L.R.C.P. LOND.

THE patient was a girl, aged 16 years. Her mother was dead but her father was alive and well. She had one brother alive who was healthy, but her three sisters were goitrous, one subsequently coming for treatment and recovering in three weeks, after taking syrup of iodide of iron and iodide of potassium and painting the gland with tincture of iodine. The patient, who was a fairly healthy looking girl, appeared to be well nourished but was a little anæmic, and she had a simple parenchymatous goitre. There had been no catamenia and slight exophthalmos was present. She had walked two miles to the surgery. She complained of difficulty in swallowing and in breathing. The tonsils were slightly inflamed. The left lobe of the thyroid was of about the size of a duck's egg and it extended behind the trachea, and was pressed down firmly upon the sternum during the act of swallowing and during inspiration. The gland was rather hard and could not be separated from the trachea. The patient was given half a drachm of syrup of iodide of iron and three grains of iodide of potassium three times a day, the gland being painted every night and morning with tincture of iodine. I was called up early on the following morning to see the patient who experienced considerable difficulty in breathing and in swallowing. There was an increase of stridor and the breathing was most comfortable when the patient was sitting up in a chair. There was no elevation of temperature and the pulse rate was 60 and of fair volume and tension. I ordered inhalations of steam, hot fomentations to be applied to the throat, and gave a gargle of chlorate of potassium and carbolic acid. The patient was more comfortable during the day. I was called up again on the next night, the messenger expressing the opinion that the patient was dying. I took with me 